\title{
SERUM VISFATIN RELATIONSHIP WITH GLYCEMIC CONTROL AND ADIPOSITY INDICES IN PATIENTS WITH TYPE 2 DIABETES MELLITUS
}

\section{Syed Shahid Habib ${ }^{\otimes}$, Shahid Bashir ${ }^{2}$, Syed Hamid Habib ${ }^{3}$}

\begin{abstract}
OBJECTIVE: To assess and compare serum visfatin levels with body composition adiposity indices and glycemic control in patients with Type 2 Diabetes Mellitus (T2DM).

METHODS: This observational case-control study was conducted at the Department of Physiology, College of Medicine and King Khalid University Hospital (KKUH), Riyadh, Saudi Arabia from April 2018 to March 2019. We studied sixty three individuals (33 T2DM and 30 controls) who were recruited from diabetes care clinics. Anthropometric, demographic and clinical characteristics were recorded from all participants and they were matched for age and gender. Venous blood samples were collected to measure visfatin and glycosylated hemoglobin (HbAlc). Adiposity indices were analyzed by Bio Impedance Analyzer (BIA).
\end{abstract}

RESULTS: Serum visfatin levels were $7.01 \pm 3.79 \mathrm{ng} / \mathrm{ml}$ in subjects with T2DM and $4.02 \pm 2.74 \mathrm{ng} / \mathrm{ml}$ in healthy subjects $(p=0.046)$. Body composition indices including BMI, BMR, body fat percentage [BF\%], body fat mass [BFM], truncal fat $[T F]$, truncal fat mass [TFM] and visceral fat [VF] differences were not statistically significant between two groups. Serum visfatin levels were $9.29 \pm 3.44 \mathrm{ng} / \mathrm{ml}$ in T2DM with poor glycemic control ( $\mathrm{HbAlc}>7.5 \%$ ) as compared to $4.24 \pm 1.87$ $\mathrm{ng} / \mathrm{ml}$ in diabetic patients with good glycemic control (HbAlc $<7.5 \%$ ) $[p=0.001]$. Visfatin positively correlated with BMI $(r=0.284, p<0.05), B F \%$ $(r=0.302, p<0.05), B F M(r=0.280, p<0.05), V F(r=0.263, p<0.05)$ and HbAlc $(r=0.394, p<0.01)$.

CONCLUSION: The results of this study show that T2DM patients have high serum visfatin levels. Moreover, higher levels of visfatin are observed with poor glycemic control and increasing body adiposity indices.

KEY WORDS: Diabetes Mellitus, Type 2 (MeSH); Visfatin (Non-MeSH); Nicotinamide Phosphoribosyltransferase (MeSH); Glycemic control (MeSH); Body fat percentage (Non-MeSH); Intra-Abdominal Fat (MeSH); Visceral fat (Non-MeSH).

THIS ARTICLE MAY BE CITED AS: Habib SS, Bashir S, Habib SH. Serum visfatin relationship with glycemic control and adiposity indices in patients with type 2 diabetes mellitus. Khyber Med Univ J 2020;12(4): 263-7. DOI: 10.35845/kmuj.2020.20254.

\section{INTRODUCTION}

Ty ype 2 Diabetes mellitus (T2DM) is an illness with multiple ramifications. Recent studies discovered a novel adipokine; visfatin [ $\mathrm{N}$ i Phosphoribosyletransferase (NAMPT) or pre-B-cell colony-enhancing factor I (PBEFI)] that are linked to T2DM which binds to insulin receptors inducing glucose utilization.' It is mostly found in visceral adipocytes which explains its up-regulation in obesity. ${ }^{2}$ Visfatin has been reported to be high in T2DM and plays an important role in the body's immune responses, metabolism and inflammation. ${ }^{3}$ Tumor Necrosis FactorAlpha (TNF- $\alpha$ ) released from glial cells is triggered by visfatin, which causes neuroinflammation. ${ }^{4}$ Animal studies suggest that intracerebroventricular
I. Department of Physiology, College of Medicine \& King Khalid University Hospital, King Saud University, Riyadh, Kingdom of Saudi Arabia.

2. Neuroscience Centre, King Fahad Specialist Hospital Dammam, Kingdom of Saudi Arabia.

3. Institute of Basic Medical Sciences, Khyber Medical University, Peshawar, Pakistan.

Email『: sshahid@ksu.edu.sa, shahidhabib44@hotmail.com

Contact \# : +966508942522

$\begin{array}{ll}\text { Date Submitted: } & \text { April 04, 2020 } \\ \text { Date Revised: } & \text { December 07, 2020 } \\ \text { Date Accepted: } & \text { December II, 2020 }\end{array}$

injection of visfatin leads to an illness responses, fever, reduced motor activity, melanocortin and also effects feeding behaviour. ${ }^{5,6}$ It is reported that there is imbalance between the protective and pro-inflammatory adipokines in T2DM, regarded as dysfunction of adipose tissues. ${ }^{7}$ This may be partly responsible for promoting diabetes complications. The role of favorable adipokines such as adiponectin, tumor necrosis factorrelated proteins, omentin and unfavorable ones like visfatin and resistin, for diagnosis and prognosis of development of cardiovascular diseases in T2DM patients are reviewed in detail. ${ }^{7}$ A strong positive correlation has been reported between visfatin level and the inflammatory markers IL-6, TNF- and CRP in T2DM. There is also a positive correlation with insulin resistance and $\mathrm{BMI}$ which indicates association of visfatin with obesity and T2DM. ${ }^{8}$ High serum leptin, resistin and visfatin in the first trimester of pregnancy are significantly altered leading to the development of gestational diabetes mellitus (GDM). Therefore, these serum markers may serve as significant predictive indices in GDM.' Although the relationship of visfatin with obesity has been studied, the relationship of body adiposity indices and relation with the glycemic 
TABLE I: COMPARISON OF CLINICAL CHARACTERISTICS BETWEEN CONTROL AND DIABETIC PATIENTS (MALE 39 AND FEMALES 24)

\begin{tabular}{|c|c|c|c|}
\hline Variables & $\begin{array}{c}\text { T2DM } \\
\text { Mean } \pm \text { SD (Range) }\end{array}$ & $\begin{array}{c}\text { Control } \\
\text { Mean } \pm \text { SD (Range) }\end{array}$ & $\begin{array}{l}\text { Significance } \\
\text { p Value }\end{array}$ \\
\hline Male/Females & $19 / 11$ & $20 / 13$ & \\
\hline Age (years) & $\begin{array}{c}54.84 \pm 9.28 \\
(25-67)\end{array}$ & $\begin{array}{c}49.38 \pm 13.58 \\
(30-80)\end{array}$ & 0.063 \\
\hline Pulse (bpm) & $\begin{array}{c}80.93 \pm 15.21 \\
(57-117)\end{array}$ & $\begin{array}{c}78.48 \pm 12.71 \\
(56-108)\end{array}$ & 0.314 \\
\hline WHR & $\begin{array}{c}0.94 \pm 0.06 \\
(.83-1.06)\end{array}$ & $\begin{array}{l}0.89 \pm 0.07 \\
(0.72-1.00)\end{array}$ & 0.447 \\
\hline $\mathrm{SBP}(\mathrm{mm} \mathrm{Hg})$ & $\begin{array}{c}142.33 \pm 20.27 \\
(101-186)\end{array}$ & $\begin{array}{c}119.07 \pm 16.43 \\
(92-156)\end{array}$ & 0.545 \\
\hline $\mathrm{DBP}(\mathrm{mm} \mathrm{Hg})$ & $\begin{array}{c}85.53 \pm 8.83 \\
(73-1 I I)\end{array}$ & $\begin{array}{c}79.47 \pm 14.75 \\
(40-107)\end{array}$ & 0.042 \\
\hline $\mathrm{FBG}(\mathrm{mmol} / \mathrm{L})$ & $\begin{array}{c}9.29 \pm 3.06 \\
(4.40-15.19)\end{array}$ & $\begin{array}{l}4.75 \pm 0.61 \\
(3.80-5.81)\end{array}$ & 0.001 \\
\hline HbAIC (\%) & $\begin{array}{c}8.26 \pm 1.35 \\
(5.70-10.80)\end{array}$ & $\begin{array}{l}5.4 I \pm 0.45 \\
(4.90-5.21)\end{array}$ & 0.009 \\
\hline Visfatin (ng/ml) & $\begin{array}{c}7.01 \pm 3.79 \\
(2.23-15.19)\end{array}$ & $\begin{array}{c}4.02 \pm 2.74 \\
(1.28-12.00)\end{array}$ & 0.001 \\
\hline
\end{tabular}

blood glucose), HbAlc (Glycosylated hemoglobin), BMR (Basal metabolic rate)

TABLE II: COMPARISON OF BODY COMPOSITION INDICES BETWEEN CONTROL AND DIABETIC PATIENTS

\begin{tabular}{|c|c|c|c|}
\hline Analytes & $\begin{array}{c}\text { T2DM } \\
\text { Mean } \pm \text { SD (Range) }\end{array}$ & $\begin{array}{c}\text { Control } \\
\text { Mean } \pm \text { SD (Range) }\end{array}$ & $\begin{array}{c}\text { Significance } \\
\text { p Value }\end{array}$ \\
\hline Male/Females & $19 / 11$ & $20 / 13$ & \\
\hline BMI $\left(\mathrm{kg} / \mathrm{m}^{2}\right)$ & $\begin{array}{c}33.27 \pm 5.81 \\
(22.50-46.40)\end{array}$ & $\begin{array}{l}31.39 \pm 7.00 \\
(22.7-40.12)\end{array}$ & 0.692 \\
\hline $\mathrm{BF} \%$ & $\begin{array}{c}38.96 \pm 7.85 \\
(24-52)\end{array}$ & $\begin{array}{c}34.63 \pm 8.69 \\
(20-49)\end{array}$ & 0.353 \\
\hline $\mathrm{BFM}(\mathrm{kg})$ & $\begin{array}{l}35.0 I \pm I I .24 \\
(20.20-71.60)\end{array}$ & $\begin{array}{l}31.19 \pm 13.18 \\
(13.70-79.40)\end{array}$ & 0.566 \\
\hline FFM (kg) & $\begin{array}{l}49.28 \pm I I .21 \\
(13.70-74.80)\end{array}$ & $\begin{array}{c}49.63 \pm 8.66 \\
(37.50-72.31)\end{array}$ & 0.499 \\
\hline VF scores & $\begin{array}{c}10.03 \pm 5.95 \\
(18.00-10.03)\end{array}$ & $\begin{array}{c}5.44 \pm 4.7 \mid \\
(5-\mid 4)\end{array}$ & 0.005 \\
\hline TF (kg) & $\begin{array}{c}38.04 \pm 5.70 \\
(26-50)\end{array}$ & $\begin{array}{c}35.18 \pm 6.31 \\
(26-46)\end{array}$ & 0.480 \\
\hline TFM (kg) & $\begin{array}{l}17.78 \pm 5.40 \\
(9.10-17.78)\end{array}$ & $\begin{array}{c}|4.67 \pm 6.4| \\
(16.21-32.80)\end{array}$ & 0.428 \\
\hline
\end{tabular}

Values are compared by

control has not been studied in detail. Therefore, in this study we aimed to study and compare serum visfatin levels with body adiposity and glycemic control in patients with T2DM.

\section{METHODS}

This observational case control study was conducted at Department of
63 were finally selected as per our inclusion criteria (33 T2DM and 30 controls). The groups were matched for age and gender (male 39 and Females 24) Subjects included had age range between 30 to 65 years and were diagnosed cases of T2DM per recent American Diabetes Association (ADA) criteria (American Diabetes Association, 2010) for at least one-year duration. All patients at the time of recruitment were in a stable metabolic state. Any patient with history of cognitive impairment or psychiatric disease (anxiety and depression), liver or renal dysfunction, acute diabetic state (diabetic ketoacidosis and hyperosmolar hyperglycemic state) and pregnancy was excluded from the study. Control group included healthy subjects from hospital staff and patients companions without any history of any ongoing acute or chronic illness. They were matched for gender, age, BMI and social status. All were having normal glucose and glycosylated hemoglobin (HbAlc) levels. The T2DM patients were divided into good and poor glycemic control group based on a cutoff $\mathrm{HbAl}$ c value of $7.5 \%$. $^{10}$

Measurements of clinical characteristics and body composition analysis

Different parameters such as detailed history, BMI, WHR (waist-hip-ratio), pulse and blood pressure (BP) was recorded. Body composition of all participants was analyzed by bioelectrical impedance analysis (BIA) using commercially available Body Composition Analyzer (Type BC-418 MA, TANITA Corporation Japan)." The bioimpedance analyzer uses eight points of tactile electrodes for making the recordings (contact at the hands and feet). This technique uses multiple frequencies to measure total body water, fats and fat free mass in total and its segmental distribution in trunk and limbs.

\section{Serum Assays}

Venous blood samples were collected from all subjects in fasting state of $10-12$ hours. Serum was separated by centrifugation at 1500 was separated 


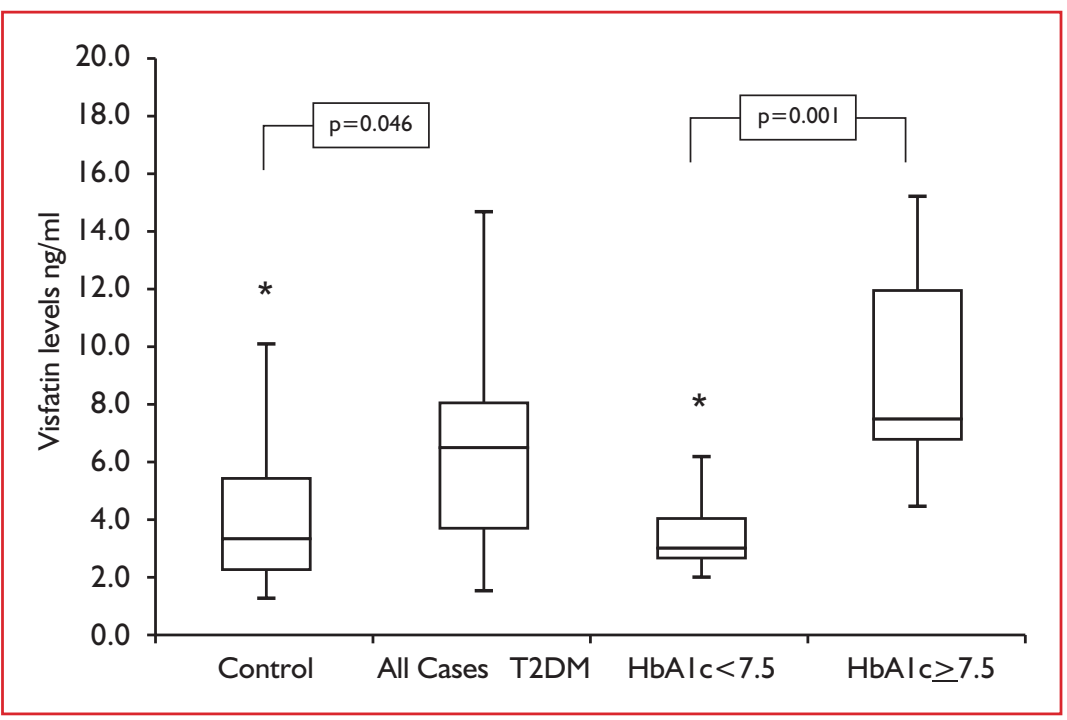

Figure I: Box plot showing comparison of serum visfatin levels between control and diabetic patients with good ( $\mathrm{HbAl} c<7.5 \%)$ and poor ( $\mathrm{HbAl} \mathrm{c} \geq 7.5 \%)$ glycemic control.

aliquoted and stored at $-80{ }^{\circ} \mathrm{C}$ until required. Blood samples were analyzed for visfatin levels, fasting blood glucose (FBG) and glycosylated hemoglobin (HbAlc).

Serum visfatin concentrations were measured by competitive enzyme immunoassay using Human VF (Visfatin) ELISA kit following manufacturer's instructions (Elabsciences Biotechnology Co., Ltd. China). Briefly pre-coated antibody specific to visfatin in the microtiter plate was reacted with samples and standards for 90 minutes at $37^{\circ} \mathrm{C}$. Following incubation, biotinylated visfatinspecific antibody was added and incubated at $37^{\circ} \mathrm{C}$ for I hour. Following washing, the Avidin-Horseradish Peroxidase conjugate was used to detect the antigen-antibody complex. An enzyme substrate was added to hydrolyze the reaction and intensity of the reaction was read at $450 \mathrm{~nm}$. The detection Range of kit was between 0.31 and $20 \mathrm{ng} / \mathrm{mL}$ with sensitivity of 0.19 $\mathrm{ng} / \mathrm{mL}$. There was no significant crossreactivity or interference between Human VF and its analogues was observed. Interassay and intra-assay coefficient of variation was kept less than $15 \%$ and $10 \%$ respectively.

\section{Statistical analysis}

Data was analyzed using SPSS (Version 21.0). All numerical data were expressed as mean and standard deviation (SD). Student's $t$ test was used for normally distributed data and Mann-Whitney $U$ test for data which was not following normal distribution. Spearman's rank order and Pearson correlations were used where needed.

\section{RESULTS}

This study assessed the correlation between serum visfatin, glycemic control (via $\mathrm{HbAlc}$ ) and body composition in T2DM subjects. The mean age of the T2DM patients was $54.84 \pm 9.28$ years compared to $49.38 \pm 13.58$ of the healthy controls.

Comparison of the anthropometric and clinical characteristics between T2DM and healthy subjects showed no significant differences in age, pulse, waist, hip, WHR, systolic BP, weight and height (Table I). Serum visfatin levels were $7.01 \pm 3.79$ $\mathrm{ng} / \mathrm{ml}$ in subjects with T2DM and $4.02 \pm 2.74 \mathrm{ng} / \mathrm{ml}$ in healthy subjects $(p=0.046)$. However, diastolic BP, FBS, and HBAlc were significantly higher in diabetics versus healthy subjects. Body composition indices such as BMI, BMR, fat mass, fat percentage, truncal fat and truncal fat mass differences were not significantly different between T2DM and control groups (Table II). Furthermore, Serum visfatin levels were $9.29 \pm 3.44$ $\mathrm{ng} / \mathrm{ml}$ in T2DM with poor glycemic control ( $\mathrm{HbAlc}>7.5 \%$ ) as compared to $4.24 \pm 1.87 \mathrm{ng} / \mathrm{ml}$ in diabetic patients with good glycemic control ( $\mathrm{HbAlc}<7.5 \%$ ) $[p=0.00 I]$, (Figure I). Visfatin correlated positively with BMI $(r=0.284, p<0.05)$, BF\% ( $r=0.302, p<0.05)$, BFM $(r=0.280$, $p<0.05)$, visceral fat $(r=0.263, p<0.05)$ and HbAlc $(r=0.394, p<0.0 \mathrm{I})$ [Table III].

\section{DISCUSSION}

This study was an effort to measure and assess serum visfatin levels and its relationship with glycemic control and body composition in patients with T2DM compared with a group of healthy control subjects. Our study showed positive correlation of serum visfatin with body adiposity and glycemic control. Serum visfatin levels are also found to be positively correlated with increasing the severity of coronary artery disease in patients having a high SYNTAX scoring which is a unique tool to score complexity of coronary artery disease. Furthermore, it can serve as a useful biomarker in predicting high SYNTAX scores in angina pectoris patients for coronary artery bypass grafting. ${ }^{12}$ Visfatin is reported to be associated with insulin resistance and exhibits proinflammatory properties.

It is also known that insulin resistance and inflammation are one of the main contributors in the pathogenesis of nonalcoholic fatty liver disease (NAFLD), however, the exact relationship between the role of visfatin in NAFLD development remains uncertain. ${ }^{13}$ The positive correlation found in our study with body adiposity provides an evidence that high levels may also be involved in the pathogenesis of fatty liver disease, and needs to be further explored. Irisin and visfatin in diabetic nephropathy patients are found to be significantly raised in comparison to T2DM without nephropathy. Furthermore, the levels were raised with the severity of nephropathy staging, suggesting the index of severity in diabetic nephropathy. ${ }^{14}$ Irisin is a myokine that is usually released from the muscle immediately after exercise. It is secreted from fibronectin type III domain containing 5 (FNDC5) after the cleavage of its extracellular portion. ${ }^{15}$ Zhang M, et al. reported the irisin is a significant marker for macrovascular disease in T2DM. ${ }^{16}$ Ebert $\mathrm{T}$, et al. reported that irisin levels were decreased in the advanced stage of the chronic kidney disease and could be used as a marker to assess the renal function. ${ }^{17}$

Serum visfatin plays significant role in numerous physiological and pathological 
processes including cardiovascular diseases, T2DM and obesity. However, the role of circulating visfatin in the pathogenesis of atherosclerotic plaque progression in T2DM, and/or association with the vascular complications remain uncertain. Although, T2DM patients with atherosclerotic plaques showed elevated levels of serum visfatin and may serve as one of the predictors of atherosclerotic plaques. ${ }^{18}$ We observed that T2DM have higher levels of visfatin compared to control subjects, despite the fact that subjects in both groups were matched for age, gender, and BMI. Similar findings were observed in a study conducted to investigate visfatin levels in newly diagnosed uncontrolled T2DM patients, where it was believed that the increase of visfatin levels was caused by hyperinsulinemia due to insulin resistance. ${ }^{19}$ Quan $X Z$, et al., observed higher levels of fatigue and exercise intolerance in visfatin transgenic mice indicating that these parameters are regulated by visfatin. ${ }^{20}$ Zhang $\mathrm{YW}$, et al., (20I5) also reported smaller hippocampal volumes in T2DM patients and memory impairments. Their findings also support our study. They observed a positive correlation between HbAlc levels, poorer memory performance and hippocampal atrophy in T2DM subjects, which was not observed in our study. However, we found that visceral fat was positively correlated with cognitive impairment in our population. ${ }^{21}$ Visceral adiposity correlated significantly with serum visfatin levels. The limitations of our study is the relatively small sample size and its cross sectional design.

\section{CONCLUSION}

The results of this study show that T2DM patients have high visfatin levels which are significantly higher in T2DM patients with poor glycemic control compared to good glycemic control. Moreover, visfatin levels are positively associated with body adiposity indices including visceral fat.

\section{RECOMMENDATIONS}

Long-term prospective trials on larger scale are needed in diabetic patients to explore the true links between T2DM and adipokines.

\section{ACKNOWLEDGMENTS}

We would also like to Mr Timhar Amlih for his cooperation and assistance.

\section{REFERENCES}

I. Chen MP, Chung FM, Chang DM, Tsai JCR, Huang HF, Shin SJ, et al. Elevated plasma level of visfatin/pre-B cell colony-enhancing factor in patients with type 2 diabetes mellitus. J Clin Endocrinol Metab 2006;9I(I):295-9. DOI: 10.1210/jc.2005-1475.

2. Adeghate E. Visfatin: structure, function and relation to diabetes mellitus and other dysfunctions. Curr Med Chem 2008;15 (I8):185I-62. DOI: | 0.2 I 74/ 092986708785 | 33004.

3. Garten A, Petzold S, Schuster S, Körner A, Kratzsch J, Kiess W. Nampt and its potential role in inflammation and type 2 diabetes. Handb Exp Pharmacol 20I I;(203): 147-64. DOI: 10.1007/978-3-642-172।4-4_7.

4. Zhao B, Zhang M, Han X, Zhang XY, Xing $Q$, Dong $X$, et al. Cerebral ischemia is exacerbated by extracellular nicotinamide phosphoribosyltransferase via a nonenzymatic mechanism. PloS One 20I 3;8(I 2):e 85403 . DOI: 10.1371/journal.pone.0085403.

5. Brunetti, L, Recinella, L, Di Nisio, C, Chiavaroli A, Leone S, Orlando G, et al. Effects of visfatin/PBEF/NAMPT on feeding behaviour and hypothalamic neuromodulators in the rat. J Biol Regul Homeost Agents 20I2;26(20):295-302.

6. Park BS, Jin SH, Park J, Park JW, Namgoong IS, Kim YI, et al. Visfatin induces sickness responses in the brain. PLoS One 201I;6(I):el598I. DOI: 10.1371/journal.pone.001598I.

7. Liang $W$, Ye DD. The potential of adipokines as biomarkers and therapeutic agents for vascular complications in type 2diabetes mellitus. Cytokine Growth Factor Rev 2019;48:32-9. DOI: $10.1016 / j$. cytogfr.2019.06.002.

8. Hetta HF, Ez-Eldeen ME, Mohamed GA, Gaber MA, ElBadre HM, Ahmed $E A$, et al. VisfatinSerum Levels in Obese Type 2 Diabetic Patients: Relation to Proinflammatory Cytokines and Insulin Resistance. Egypt J Immunol 20 I8;25(2): I4I-5I.

9. Bawah AT, Seini MM, Abaka-Yawason A, Alidu $H$, Nanga S. Leptin, resistin andvisfatinas useful predictors of gestationaldiabetes mellitus. Lipids Health Dis 2019 Dec 13;18(I):221. DOI: I0. I I86/s I 2944-019-I I69-2.

10. American Diabetes Association. Standards of medical care in diabetes 2010. Diabetes Care 2010;33(Suppl I):SII-S6I. DOI: 10.2337/dcI0SOII.

TABLE III: SPEARMAN'S CORRELATION BETWEEN SERUM VISFATIN, BODY COMPOSITION AND GLYCEMIC CONTROL

\begin{tabular}{|c|c|c|c|c|c|c|c|c|c|c|}
\hline & AGE & WHR & SBP & DBP & BMI & BF\% & BFM & VF & HbAIC & Visfatin \\
\hline AGE & 1.000 & & & & & & & & & \\
\hline WHR & 0.184 & 1.000 & & & & & & & & \\
\hline SBP & 0.592 *** & 0.272 & 1.000 & & & & & & & \\
\hline DBP & 0.130 & 0.36 I* & 0.544 *** & 1.000 & & & & & & \\
\hline BMI & -0.101 & 0.090 & -0.004 & -0.023 & 1.000 & & & & & \\
\hline BF\% & -0.007 & 0.197 & 0.054 & 0.034 & $0.759 * *$ & 1.000 & & & & \\
\hline BFM & -0.095 & 0.170 & -0.046 & -0.031 & $0.923^{* *}$ & 0.872 *** & 1.000 & & & \\
\hline VF & 0.083 & $0.24 I$ & 0.126 & 0.104 & 0.585 *** & $0.684 * *$ & 0.636 *** & 1.000 & & \\
\hline $\mathrm{HbAlc}$ & $0.404 * *$ & $0.357^{*}$ & $0.548 * *$ & 0.204 & 0.406 ** & 0.423 *** & 0.383 *** & 0.490*** & 1.000 & \\
\hline Visfatin & 0.135 & 0.118 & 0.173 & 0.123 & $0.284 *$ & $0.302^{*}$ & $0.280 *$ & $0.263 *$ & $0.394 * *$ & 1.000 \\
\hline
\end{tabular}

${ }^{*} p<0.05, *{ }^{* * p}<0.01$; WHR (Waist-hip-ratio), SBP (Systolic blood pressure), DBP (Diastolic blood pressure), BMI (Body mass index), BF\% (Body fat percentage), BFM (Body fat mass), VF (Visceral fat), HbAlc (Glycosylated hemoglobin) 
II. Habib SS. Serum resistin levels in patients with type 2 diabetes mellitus and its relationship with body composition. Saudi Med J 2012 May;33(5):495-9.

12. Duman H, Özyıldız AG, Bahçeci i, Duman H, Uslu A, Ergül E. Serumvisfatinlevel is associated with complexity of coronary artery disease in patients with stable angina pectoris. Ther Adv Cardiovasc Dis 2019 JanDec;13:17539447 19880448. DOI: I0.1 |77//7539447/9880448.

13. Heo YJ, Choi SE, Jeon JY, Han SJ, Kim DJ, Kang $Y$, et al. Visfatinlnduces Inflammation and Insulin Resistance via the NF- B and STAT3 Signaling Pathways in Hepatocytes. J Diabetes Res 2019 Jul I7;2019: 402।623. DOI: 10.1155/2019/4021623.

14. Mageswari R, Sridhar MG, Nandeesha $\mathrm{H}$, Parameshwaran S, Vinod KV. Irisin andVisfatinPredicts Severity of Diabetic Nephropathy. Indian J Clin Biochem 2019 Jul;34(3):342-6. DOI: |0.|007/s |229|-0|8-0749-7.

15. Guo A, Li K, Xiao Q. Sarcopenic obesity: Myokines as potential diagnostic biomarkers and therapeutic targets? Exp Gerontol 2020 Oct I; I39:1। 1022. DOI: 10.1016/j.exger.2020.111022.

16. Zhang M, Chen P, Chen S, Sun Q, Zeng $\mathrm{QC}$, Chen JY, et al. The association of new inflammatory markers with type 2 diabetes mellitus and macrovascular complications: a preliminary study. Eur Rev Med Pharmacol Sci 2014 Jun; I8(II):I567-72.

17. Ebert T, Focke D, Petroff D, Wurst U, Richter J, Bachmann A, et al. Serum levels of the myokine irisin in relation to metabolic and renal function. Eur J Endocrinol 2014 Mar 8; I 70(4):50I-6. DOI: 10.1530/EJE-13-1053.

18. Zheng LY, Xu X, Wan RH, Xia S, Lu J, Huang Q. Association between serumvisfatinlevels and atherosclerotic plaque in patients with type 2diabetes. Diabetol Metab Syndr 2019 Jul 24;1।:60. DOI: 10.1186/s |3098-0| 9-0455-5.

19. Dogru T, Sonmez A, Tasci I, Bozoglu E, Yilmaz MI, Erdem G, et al. Plasma visfatin levels in patients with newly diagnosed and untreated type 2 diabetes mellitus and impaired glucose tolerance. Diabetes Res Clin Pract 2007 Apr 1;76(I):24-9. DOI: 10.1016/j.diabres.2006.07.03। .

20. Quan XZ, Dong W, Gao K, Su W, Zhang LF. The Effect of Visfatin on Blood Glucose and Locomotor Activity in the Visfatin Transgenic Mouse. Chin J Comp Med 2009;(09): I I-5.

21. Zhang YW, Zhang JQ, Liu C, Wei P, Zhang X, Yuan QY, et al. Memory dysfunction in type 2 diabetes mellitus correlates with reduced hippocampal $\mathrm{CAI}$ and subiculum volumes. Chin Med J (Engl) 20I5; I28(4):465-7I . DOI: 10.4103/0366-6999.151082.

\section{DISCLAIMER}

The manuscript-based abstract was published as part of special issue: "Abstracts of the $3 I^{\text {st }}$ International Congress of Clinical Neurophysiology (ICCN) of the IFCN, May I - 6, 2018, Washington, DC, USA". Available from URL: https://www.sciencedirect.com/science/article/pii/SI3882457|8307272. DOI: 10.1016/j.clinph.2018.04.428.

\section{AUTHORS' CONTRIBUTIONS}

Following authors have made substantial contributions to the manuscript as under:

SSH: Conception and study design; acquisition, analysis and interpretation of data, drafting the manuscript, approval of final version to be published

SB: Acquisition of data, drafting the manuscript, critical review, approval of final version to be published

SHH: Analysis and interpretation of data, drafting the manuscript, critical review, approval of final version to be published

Authors agree to be accountable for all aspects of the work in ensuring that questions related to the accuracy or integrity of any part of the work are appropriately investigated and resolved.

\section{CONFLICT OF INTEREST}

Authors declared no conflict of interest GRANT SUPPORT AND FINANCIAL DISCLOSURE

Work on this study was supported by Deanship of Scientific Research (Grant Number: RGP-1438-048) King Saud University, Riyadh, Saudi Arabia

\section{DATA SHARING STATEMENT}

The data that support the findings of this study are available on request from the corresponding author. The data are not publicly available due to privacy or ethical restrictions.

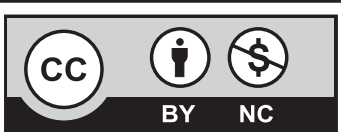

This is an Open Access article distributed under the terms of the Creative Commons Attribution-Non Commercial 2.0 Generic License. 